\title{
Correction to: Estimation in Constant Stress Partially Accelerated Life Tests for Weibull Distribution Based on Censored Competing Risks Data
}

\author{
Amal S. Hassan ${ }^{1}$ - . Said G. Nassr² ${ }^{2}$. Sukanta Pramanik ${ }^{3}$. Sudhansu S. Maiti ${ }^{4}$
}

Published online: 18 April 2020

๑) Springer-Verlag GmbH Germany, part of Springer Nature 2020

\section{Correction to: Annals of Data Science (2020) 7(1):45-62 https://doi. org/10.1007/s40745-019-00226-3}

In the original publication of the article the ORCID ID of the co-author Amal S. Hassan has been published incorrectly. The corrected ORCID ID should appear as https://orcid.org/0000-0003-4442-8458.

Publisher's Note Springer Nature remains neutral with regard to jurisdictional claims in published maps and institutional affiliations.

The original article can be found online at https://doi.org/10.1007/s40745-019-00226-3.

Said G. Nassr

dr.saidstat@gmail.com

1 Faculty of Graduate Studies for Statistical Research, Cairo University, Giza, Egypt

2 Faculty of Business Administration and International Marketing, Sinai University, North Sinai, Egypt

3 Department of Statistics, Siliguri College, North Bengal University, Siliguri 734 001, India

4 Department of Statistics, Visva-Bharati University, Santiniketan 731 235, India 